\title{
CRÔNICA ESPORTIVA BRASILEIRA: HISTÓRICO, CONSTRUÇÃO E CRONISTA
}

\author{
Felipe Rodrigues da Costa* \\ Amarílio Ferreira Neto** \\ Antonio Jorge Gonçalves SoARes ${ }^{* * *}$
}

\section{RESUMO}

A crônica há muito tempo tem sido utilizada nos meios de comunicação, sobretudo no jornalístico. $\mathrm{Na}$ área esportiva brasileira, a crônica aborda as diferentes modalidades, principalmente o futebol, que servirá como referência para a discussão do nascimento da crônica na França, da sua construção como gênero literário, da chegada ao Brasil e seu desenvolvimento como gênero nacional e do papel do cronista na sua transformação. Este artigo faz uma revisão da literatura para construir o histórico da crônica no Brasil, associando o futebol à "nacionalização" e difusão desse gênero narrativo.

PALAVRAS-CHAVE: futebol - crônica esportiva - cronista

\section{INTRODUÇÃO}

crônica hoje se enquadra como gênero literário de assunto livre,
de registro de pequenos fatos do cotidiano sobre política, arte, esporte e variados temas. Por se tratar de assuntos considerados menos importantes e por ser um texto limitado espacialmente nas edições dos jornais nas colunas ou em artigos opinativos, a crônica é tida como um gênero menor, o que, talvez, seja essa característica que permita ao cronista analisar "as pequenas coisas que as grandes vistas não percebem" (LUCENA, 2003, p. 162).

* Aluno do Curso de Especialização em Futebol da UFV, licenciado em Educação Física pela UFES e membro do Instituto de Pesquisa em Educação e Educação Física (PROTEORIA).

** Professor doutor do Centro de Educação Física e Desportos da UFES e coordenador do Instituto de Pesquisa em Educação e Educação Física (PROTEORIA).

*** Professor Doutor titular da Universidade Gama Filho e coordenador do programa de pós-graduação da Universidade Gama Filho. 
A crônica conhecida nos dias de hoje, no Brasil, nasceu nos folhetins franceses (século XIX), nos rodapés dos jornais, para entreter os leitores, aparecendo em 1799, no Journal Dibats, em Paris, com JulienLouis Geoffrou "fazendo crítica diária da atividade dramática" (MOISÉS, 1982, p. 245).

Nos espaços de rodapé, começaram a aparecer textos de ficção, nascendo, assim, o folhetim romance e o folhetim variedades. $\mathrm{O}$ folhetim romance era desenvolvido em capítulos, o que permitia que o leitor acompanhasse a história dia a dia pelos jornais. Já o folhetim que deu origem ao gênero crônica foi o folhetim variedades. Lucena (2003, p. 164) descreve as transformações operadas nesse gênero de jornalismo: "de onde ela emerge, a crônica vai instaurar rupturas tanto do ponto de vista lingüístico quanto, e principalmente, do ponto de vista temático". O argumento central é que a crônica pode ser não ficcional, na medida em que deriva de fatos do cotidiano, ao mesmo tempo em que pode possuir uma dimensão ficcional, quando possibilita ao autor construir diálogos e acrescentar personagens, além das características poéticas também pertinentes à crônica. Mas esse sentimento "não pode ser a simples expressão de uma dor de cotovelo, mas acima de tudo um repensar constante pelas vias da emoção aliada à razão [...] papel [que] se resume no que chamamos de lirismo reflexivo" (SÁ, 2002, p. 13).

Dessa forma, o presente artigo objetiva estabelecer a relação entre a crônica esportiva e o futebol no Brasil: a crônica como objeto que busca seu espaço nos meios de comunicação e o futebol se desenvolvendo como esporte popular.

O jornal se apresenta para nós como um veículo de

manutenção e "construção" de um passado que assume significados no presente da notícia [...] no caso do futebol, as narrativas jornalísticas apresentam sua memória resgatando fatos, imagens, ídolos, êxitos e fracassos anteriores, no sentido de construir uma tradição, como um elo entre as gerações dos aficionados pelo esporte (SALVADOR et al., 2005, p. 2).

\section{A CRÔNICA NO BRASIL}

Chegando ao Brasil, a crônica ganhou nova roupagem, a ponto de exclamarem que esse gênero seria tipicamente brasileiro: 
a crônica assumiu entre nós caráter sui generis. Em outros termos, estamos criando uma nova forma de crônica (ou dando erradamente esse rótulo a um gênero novo) que nunca medrou na França. Crônica é para nós hoje, na maioria dos casos, prosa poemática, humor lírico, fantasia, etc., afastando-se do sentido de história, de documentário que lhe emprestam os franceses (MOISÉS, 1982, p. 246).

Para alguns, a crônica foi naturalizada brasileiro-carioca:

se gaulesa na origem, a crônica naturalizou-se brasileira, ou melhor, carioca: é certo que há cronistas, e de mérito, em vários Estados onde a atividade jornalística manifesta vibração algo mais do que noticiosa, - mas também é certo que, pela quantidade, constância e qualidade de seus cultores, a crônica semelha em produto genuinamente carioca (MOISÉS, 1982, p. 246).

Naturalização essa que, para Moisés (1982), foi conseguida pelas profundas transformações promovidas pelos escritores brasileiros, sobretudo os cariocas, não só pela qualidade dos cronistas, mas também pela quantidade e pela constância com que publicavam. O Rio de Janeiro, quando a crônica ganha força no início do Séc. XX, era a capital da República e um palco central de acontecimentos. Teria sido Mario Filho que, trazendo uma nova forma de escrita, ${ }^{1}$ um estilo mais simples, sepultou a escrita de fraque dos antigos cronistas esportivos. Seria ele a referência do nascimento da crônica esportiva, incorporando ao gênero, além da nova linguagem, respeitabilidade ao ofício da crônica:

Mario Filho inventou uma nova distância entre o futebol e o público. Graças a ele, o leitor tornou-se tão próximo, tão íntimo do fato. E, nas reportagens seguintes, iria enriquecer o vocabulário da crônica de uma gíria irresistível. E, então, o futebol invadiu o recinto sagrado da primeira página [...]. Tudo mudou, tudo: títulos, subtítulos, legendas, clichês [...]. O cronista esportivo começou a mudar até fisicamente. Por outro lado, seus ternos, gravatas e sapatos acompanharam a fulminante ascensão social e econômica. Sim, fomos profissionalizados por Mario Filho (RODRIGUES, 1987, p. 137-138).

Foi no Rio de Janeiro que se iniciou a atividade folhetinesca. Durante a década de 1930, tido como o ano da aceitação da crônica, após 
duas décadas de divulgação, a nação passava por momento político delicado. "Tratava-se de um período da história do Brasil que se caracteriza pelo reformismo. A substituição, pura e simples, de um segmento das classes políticas dominantes por outro, sem que isso significasse qualquer transformação de base no país" (CALDAS, 1990, p. 179).

Esse quadro político nacional estimularia a publicação de material crítico daqueles que estavam inseridos no processo, contra ou a favor do regime instaurado. "O contexto em que se dava essa produção é que apresentava uma novidade: a correlação entre artista e intelectual de um lado, e Estado e sociedade de outro" (CALDAS, 1990, p. 181). Nesse contexto de efervescência cultural, a crônica já estava legitimada como gênero, mas, desde a década de 1910, o futebol, em conjunto com outros assuntos, já estava presente nas penas de cronistas famosos: os grandes responsáveis por essa aceitação da crônica no Brasil foram João do Rio (1900 - 1920) iniciando o processo de divulgação desse gênero; depois com Rubem Braga, na década de 1930, seguido de vários outros, como Fernando Sabino, Drummond de Andrade, Paulo Mendes Campos (MOISÉS, 1982). Esse mesmo contexto contribui também para mudanças literárias no País. Com a Academia Brasileira de Letras perdendo prestígio no cenário instituído, bem como a literatura de estilo rebuscado, caracterizada pelos escritos de Rui Barbosa, a chegada dos modernistas influenciou a entrada de uma nova perspectiva literária.

Pensamos que a crônica, nascida nos folhetins franceses e construída ao estilo francês, chega ao Brasil e sofre adaptações lingüísticas e temáticas, de maneira tão profunda que passa a ser considerada um gênero brasileiro. Moisés (1982) afirma que adaptação do gênero à realidade brasileira ou a apropriação do termo acabou por constituir-se num novo estilo de retratar o cotidiano. Nos termos de Burke (2003, p. 32) poder-se-ia pensar que estamos diante do processo de circularidade cultural, isto é, "cada imitação é também uma adaptação".

Esse processo de adaptação criou a marca do uso metafórico das palavras e os processos lingüísticos ${ }^{2}$ trabalhados na crônica brasileira, sobretudo, na esportiva. Esses usos teriam sido peças fundamentais para a constituição da crônica no Brasil e caracterização do gênero como brasileiro e carioca. Um cronista que trabalha de maneira diferenciada a linguagem é Armando Nogueira: 
Sua crônica reveste-se, assim, dos efeitos catárticos, por transmudar em palavra poética, pelo viés da subjetividade, os sentimentos que subjazem à representação das coisas e objetos e por evocar as imagens mítico-simbólicas que ressoam no imaginário do futebol [...]. Desta forma, Nogueira redefine a crônica de futebol, ao reorientar para o poético, em função de uma linguagem mítico-metafórica, um percurso supostamente referencial e, ao inserir nele as aspirações humanas dos aficionados por esse esporte [...] sua crônica, pelas implicações lingüísticas da subjetividade do narrador, contribui para a classificação da crônica de futebol como um subgênero (RAMADAN, 1997a, p. 26).

No jornalismo esportivo brasileiro, Armando Nogueira é um exemplo da construção da crônica poética, ficcional. Esse cronista usa "adjetivações valorativas, ritmo, jogo de imagens, subterfúgio da metáfora" (RAMADAN, 1997a, p. 29) Em outra direção, Tostão situa sua narrativa na dimensão não ficcional (real) enfatizando as análises táticas e técnicas do futebol.

Essas formas diferentes de escrever nos levam a crer que a crônica pode ser construída no campo poético e no campo jornalístico. A crônica "poética", "atemporal", "ficcional" tem suas características próximas do conto, mas se diferenciam quanto ao tamanho e, principalmente, quanto à intensidade poética. Já a crônica jornalística, temporal, tem a coluna como sua semelhante. Porém, a coluna procura relatar e à crônica é permitida a opinião.

A quantidade ${ }^{3}$ de cronistas e a qualidade apresentada nos textos mais o uso da metáfora em grande escala transformaram um gênero estrangeiro na terra que configuraria o "país do futebol". A crônica no Brasil acompanhou as modificações ocorridas no esporte e, em relação ao futebol, pode-se perceber que os assuntos são buscados também pela evolução desse esporte contando os feitos dos craques nas décadas de 1930, 1940 e 1950; nas décadas de 1960 e 1970 com a inclusão da discussão das táticas desenvolvidas; e atualmente temos o planejamento físico e as jogadas ensaiadas em destaque (MARQUES, 2000).

Trouche (2002) considera as décadas de 1920, 1930 e 1940 como sedimentadoras da prática do futebol, massificando e "transformando o futebol, mais do que em esporte nacional, numa verdadeira paixão popular mobilizando um contingente de centenas de milhares de praticantes e torcedores a cada final de semana". 
Uma breve observação nos periódicos nas primeiras décadas do século $\mathrm{XX}$ nos permite dizer que a imprensa do Rio de Janeiro ampliou o espaço dedicado aos esportes. Esta ampliação se dá no momento em que a imprensa se direciona para o amplo público que se formava em torno do futebol, tomando como alicerce o caráter empresarial que caracterizava os grandes jornais (BOTELHO, 2006, p. 328).

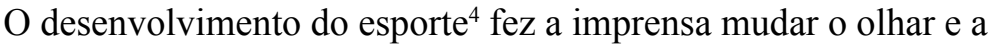
maneira de trabalhar a formação profissional da área. A editoria de esportes, antes considerada um ofício para iniciantes, uma escola para os novos profissionais da imprensa, com a evolução do esporte e a especialização ${ }^{5}$ profissional, mudou o conceito acerca do esporte e reescreveu o perfil do jornalista esportivo: além de saber regras, devia conhecer "história, personagens, fatos, evolução nos tempos, implicação cultural e social" (COSTA, 2001, p. 31).

A caracterização de que o esporte seria, dentro dos jornais, uma editoria que acolhe profissionais com pouca experiência/conhecimento teria contribuído, também, para que a crônica esportiva fosse tratada como gênero menor. Para Trouche (2002), os anos 1960 e 1970

representam indiscutivelmente o apogeu do futebol brasileiro em todos os sentidos e é neste contexto que a crônica esportiva conquista espaço definitivo nos principais órgãos de imprensa do país e, principalmente, se profissionaliza definitivamente, adquirindo contornos poéticos próprios, e redesenhando novas fronteiras para o universo do literário.

Reforça essa idéia o discurso abaixo, que inclui outros segmentos da cultura social envolvidos na difusão do esporte:

o futebol, a literatura, a imprensa e a música popular constituíram no Brasil um poderoso tripé para a implementação e - principalmente - a popularização do esporte nas grandes cidades do país. Escritores, jornalistas e músicos assumiram através de seus trabalhos um diálogo constante com seus pares e com os torcedores. Ao mesmo tempo, participaram ativamente do cotidiano do esporte, atuando não só como agentes culturais, mas também como cronistas, narradores esportivos, diretores de clubes, compositores de hinos e até mesmo como jogadores. As relações entre futebol, literatura, imprensa a música popular brasileira são, portanto, mais do que uma relação estética ou de ins- 
piração temática, constituindo um novo espaço popular na sociedade (COELHO, 2006, p. 231).

Apesar disso, Lucena (2003) aponta que, com o passar dos dias, a crônica sofre com a perda do seu vigor. Com sua fase áurea, entre as décadas de 1950 e 1970, a crônica teria perdido sua força, talvez por dois motivos: o surgimento da televisão e a inexpressividade dos cronistas que surgiam. Porém, Ramadan (1997a, p. 18) nos remete ao fato de que, ao contrário do que se pensa, a crônica conquistava mais espaços:

Estas previsões pessimistas caem por terra se examinarmos jornais e revistas de grande circulação. Em quase todos [...] há um espaço cada vez maior destinado à voz dos cronistas. E pode-se afirmar que a crônica revitalizou-se de tal forma que, hoje, encontra-se em grau de especialização. Assim se explica a crônica humorística de Jô Soares e Luís Fernando Veríssimo, publicada em jornais e revistas da atualidade, ou a futebolística de Armando Nogueira.

Em outro momento, o jornalismo esportivo perdeu força com o profissionalismo do futebol. Enquanto o futebol seguia amador, a Associação de Cronistas Desportivos (ACD) promovia o Torneio Initium, no Rio de Janeiro. Iniciado em 1916, durou até 1977, com o objetivo de incentivar torcedores a acompanhar suas equipes no campeonato estadual.

Esta imprensa escrita tem uma grande importância no que diz respeito ao desenvolvimento do futebol como objeto de consumo, a partir do momento em que o esporte ocupa, de maneira ampliada, o universo temático dos jornais. Assim o futebol passa a ser considerado um elemento que vai ajudar a ampliar as vendas de determinado periódico, à medida que este aumenta o espaço de atuação dos cronistas esportivos. A ACD começa a perder sua força à medida que o futebol e o jornalismo começam efetivamente a profissionalizar-se. Com o enfraquecimento do amadorismo, a partir de 1923, o futebol começa lentamente a deixar de ser organizado pelos jornalistas. E finalmente, em 1933, passa a girar inteiramente numa órbita profissional (BOTELHO, 2006, p. 330).

Para Normando (2003), o desinteresse ${ }^{6}$ relacionado com o futebol estava presente na área acadêmica, e a produção acerca da temática "futebol" estava fortemente associada aos cronistas esportivos: 
O futebol, por volta da segunda metade do século XX, deixou de freqüentar a pauta de interesse acadêmico ou, pelo menos, teve drasticamente diminuído as pesquisas e a divulgação do trabalho intelectual sobre a temática. À exceção mais notória de um punhado de cronistas esportivos - dos quais o maior exemplo talvez tenha sido Nelson Rodrigues -, poucos se dignaram a olhar o jogo de bola com uma perspectiva investigativa mais profunda.

A fase de crescimento da crônica se relaciona com o aumento dos interessados em esporte, e isso, conseqüentemente, se deve ao desenvolvimento do esporte. O futebol, que aos poucos caía no gosto popular e passava a movimentar os populares, deixando o turfe e as regatas em segundo plano, formou cronistas e público. Em 1900, Olavo Bilac já escrevia crônicas descrevendo o cotidiano da cidade; em 1878, Machado de Assis já discorria sobre turfe; em 1884, havia crônica sobre regatas (LUCENA, 2001).

Assim, o cotidiano metropolitano ganhava mais um acontecimento a ser contado: o esporte. Com seu desenvolvimento, ganhava cada vez mais espaço e se inseria no cotidiano da cidade e no gosto popular. Aqueles que escreviam sobre o dia-a-dia da cidade passaram a observar essa nova realidade. As crônicas sobre o esporte - e, sobretudo o futebol - ganhavam a alcunha de crônica esportiva, "num exemplo da relação que se aprofundava entre a linguagem jornalística e a crônica, que vai passo a passo se constituindo num gênero-síntese" (LUCENA, 2003, 167). É o que argumenta Marques (2000, p. 4):

O papel da simplicidade, brevidade e graça, próprias da crônica deixa de ser comentário argumentativo e expositivo, para colocar de lado a seriedade nos problemas e transformar-se em aparente "conversa fiada". Seu amadurecimento se dá numa composição de um fato miúdo, analisado com um toque humorístico e mais um quantum satis de poesia.

A relação com o Rio de Janeiro pode ter se estabelecido em conseqüência de esta cidade ser o pólo esportivo do País na época e ainda contar com grandes escritores. Além disso, a rápida propagação do esporte nos subúrbios da cidade, inclusive com fundação de clubes que agregavam os moradores de bairros-sede dessas associações que, es- 
tatutariamente não excluíam a participação de sócios por raça, credo, posição social, formava grande público praticante e leitor de crônicas esportivas (PEREIRA, 2000).

Tentando compreender a difusão das práticas esportivas no Rio de Janeiro do século XIX e no período de transição para o século XX, Melo (1999) vai apelar também às crônicas como uma forma de melhor visualizar o contexto em que estavam "crescendo" as ações nos diferentes esportes. Para Melo, era também importante assumir que a crônica, da forma como ela se constrói entre nós e em especial no Rio de Janeiro, que tem uma forte ligação com esse gênero, torna-se uma fonte relevante que nos permite ter acesso aos pequenos fatos do cotidiano (LUCENA, 2003, p. 162).

Como já foi visto, da mesma forma que a crônica transita entre o ficcional e o não ficcional, ela também o faz entre o literário e o jornalístico. Pensamos que a crônica esportiva pese mais para o lado jornalístico, analisando os fatos recorrentes, porém com o adicional da liberdade do cronista em transformar a notícia. Costa (2001, p. 53) argumenta a favor de uma análise esportiva mais próxima do cotidiano, quando diz que "o escritor esportivo se apóia no real, se compromete de alguma forma, com a realidade de um fato". Neste ponto entre ficcional e histórico/real, percebemos que o ficcional existe, mas a essência da crônica esportiva no Brasil, publicada em jornais, não tende a ficcionar os fatos, ${ }^{7}$ que são contados pelo olhar e experiência de quem vê, e seu discurso é elaborado pelo fato em si.

Tentando buscar uma maneira de classificar - sem qualificar - as estruturas temáticas das crônicas esportivas, teríamos, então, os poetas, que, segundo Trouche (2002), numa explicação de fácil entendimento, sem entrar nos méritos lingüísticos, resume estas crônicas como "uma conversa que promove um evidente processo de ficcionalização, capaz de transformar uma partida numa batalha épica, e jogadores em personagens e heróis e/ou vilões"; os críticos/opinativos, que seriam os mais numerosos, que atuam "no propósito imediato de comentar e analisar temas de eventos do cotidiano da prática do futebol [...] praticado por um grupo bastante heterogêneo - incluindo aí alguns ex-jogadores como Paulo Roberto Falcão e Tostão". 


\section{O CRONISTA}

O cronista faz uso de citações de personalidades e fatos históricos. Inserido em um contexto que possibilita o uso do recurso "ficção", busca soluções criativas na sua imaginação, sem comunicar agressividade.

Usa de uma densidade característica, pois é essa densidade a linha tênue entre crônica e conto. No conto, o autor mergulha no universo do personagem, do tempo, do espaço e da atmosfera que darão força ao "fato exemplar", o cronista age de maneira mais solta, dando a impressão de que pretende apenas ficar na superfície de seus próprios comentários (SÁ, 2002, p. 9).

É importante que o cronista não ultrapasse a fronteira existente entre crônica e conto, sendo a poesia uma das mediadoras dessa passagem: "Não estranha, por isso, que a poesia seja uma de suas fronteiras, limite do espaço em que se movimenta livremente; e o conto, a fronteira de um território que não lhe pertence" (MOISÉS, 1982, p. 255).

Ludicamente o cronista percorre a cidade. Ouve conversas, recolhe frases interessantes, observa as pessoas, registra situações [...] através do olhar de quem brinca e, pelo jogo da brincadeira, reúne forças para superar a realidade sufocante. É nesse contexto que o fato em si ganha mais importância do que os personagens (SÁ, 2002, p. 45).

Ainda sobre a percepção do cronista, Moisés (1982, p. 255) trata da impessoalidade destinada à crônica:

A impessoalidade é não só desconhecida como rejeitada pelos cronistas: é a sua visão das coisas que lhes importa e ao leitor; a veracidade positiva dos acontecimentos cede lugar à veracidade emotiva com que os cronistas divisam o mundo.

Além das características lingüísticas, impessoalidade é fundamental para a construção da crônica, exatamente para mostrar a opinião do escritor para que o texto seja formado.

Tostão nos serve como exemplo para que tratemos de impessoalidade. As concepções táticas e suas evoluções, seleção brasileira, 
jogadores e conceitos técnicos das posições têm em suas crônicas as experiências pessoais como filtro para a produção do texto. Exatamente este "filtro" - suas experiências pessoais - direciona a escrita do cronista e o estilo do seu texto, demonstrando claramente a força opinativa da crônica. Essa "veracidade emotiva" deve ser avaliada pelo cronista para que não tenha como produto final um conto, e a presença de sua opinião no que escreve o diferencia de um escritor de colunas. Somadas às temáticas já citadas, formação de talento e as "escolas" de futebol no Brasil constituem aproximadamente $32 \%$ dos assuntos tratados por ele, de 1997 a 2005 . A opinião presente nos textos é clara e consistente: trata dos assuntos com a sua experiência de maior jogador mineiro da década de 1960 e com a passagem na seleção brasileira, conquistando o tricampeonato mundial em 1970; após abandonar precocemente o futebol se tornou médico, professor universitário e se afastou do futebol para retornar a esse esporte na condição de cronista esportivo. O "filtro" que move a sua escrita ainda se constitui de 20 anos afastado do futebol, o esporte que o projetou para o mundo, as críticas por essa postura e sua estréia no mundo jornalístico. Sua escrita técnica, direta e, sobretudo, honesta, é resultado da sua vasta experiência pessoal e profissional que o aproxima da crônica jornalística e o afasta da crônica poética.

Dentro do grupo dos cronistas poéticos, estão, além de Armando Nogueira, o carioca Mario Filho e seu irmão Nelson Rodrigues. O futebol, para esses cronistas, é motivo de poesia, por essa razão eles muitas vezes deslizam seus comentários do campo técnico e tático do futebol para pensar a natureza humana a partir daí.

A crônica possibilita ao autor abordar diversos assuntos num mesmo texto que lhe permitam, ao final, amarrar as matérias que escolheu. Bender e Laurito (1993, p. 50) relacionam essa gênese da crônica - jornalismo e literatura - como uma dificuldade de definir o gênero: "Até onde vai o jornalista e termina o escritor?", perguntam. Por todas as características que permitem uma crônica ser uma crônica, emendam: "Logo não vamos esperar que a Academia Brasileira de Letras" decida conceituar nossa crônica. É crônica e só. Todos sabem do que estamos falando" (BENDER; LAURITO, 1993, p. 44). Esse apelo expressa, entre outros fatos, a simplicidade da crônica e o sentimento de posse do gênero. A fala de discordância por uma definição da crônica 
demonstra um gênero popular lutando contra uma possível dominação de instâncias superiores.

A liberdade de escrita na construção da crônica é tão grande que também a falta de assunto pode levar à transformação do autor em personagem, atitude chamada de persona literária (POLETTO, 2003). Assim, experiências pessoais ${ }^{9}$ se transformam em mote para que uma crônica tenha início: "há a importância dos estereótipos ou esquemas culturais na estruturação e na interpretação do mundo" (BURKE, 2003, p. 26).

\section{CONSIDERAÇÕES FINAIS}

Como se pode perceber, o entendimento da crônica não se mostra tão simples. A crônica se torna um gênero ambíguo em sua criação, transitando entre o literário e o jornalístico, o que influencia diretamente sua escrita e permite ao cronista opções únicas de construção de texto. Fatores como linguagem, ora poética ora coloquial, fatos reais sendo ficcionados e outras crônicas podendo ser usadas como fonte, construídas no ou para o jornal, transformando-se em temporal ou atemporal, constituem a riqueza da crônica, ampliando as possibilidades de compreensão e construção.

A partir disso, pode-se pensar o uso errado do termo cronista para definir aquele que escreve sobre o cotidiano e que adiciona ao texto sua opinião, o que poderia caracterizar uma coluna. Por outro lado, o uso demasiado poético na construção da crônica poderia transformá-la em um conto. Porém, a origem da crônica e a liberdade de escrita presente nesse gênero permitem que tenhamos esse contexto quando procuramos definir os limites de sua construção. O esporte, sobretudo o futebol, trouxe uma nova forma de escrita, novos conceitos de construção da crônica no Brasil, massificou o gênero entre os populares e incentivou a profissionalização dos profissionais envolvidos no jornalismo esportivo.

Dessa forma, consideramos que o fato de a crônica esportiva no Brasil se fazer mais jornalística que poética se dá pela interpretação condicionada pelas experiências do narrador, ${ }^{10}$ influenciada pelas estruturas lingüísticas utilizadas que foram incorporadas e desenvolvidas durante o processo de construção da crônica esportiva. Essa característica pessoal influencia sobremaneira a construção opinativa presente na 
crônica brasileira, caracterizando-a e diferenciando-a de outras formas de escrita.

Considerando a existência de dois estilos de se fazer crônica esportiva no Brasil, a forma noticiosa, mais crítica do cotidiano, de análise do esporte, do jogo, é mais freqüente nos jornais, escrita para os jornais. A crônica esportiva, com tom mais poético, menos realista, com personagens, é uma vertente também utilizada no Brasil, porém o estilo mais utilizado pela crônica esportiva nacional é o informativo, noticioso.

The brazilian sports chronicle: history, construction and the sports chronicler

\begin{abstract}
The chronicle has long been used in the media, especially in journalism. In the Brazilian sports field, the chronicle has tackled the many sports categories, mainly football, which will be used as a reference for the discussion on the origins of the chronicle in France, its construction as a literary genre, its arrival in Brazil and its development as a national genre, as well as the role of the chronicler in transforming the genre. This article reviews the available literature in order to build the history of the chronicle in Brazil and associates football to the nationalization and spread of this narrative genre.
\end{abstract}

KEYWORDS: football - sports chronicle - chronicler

\title{
Crónica deportiva brasileña: histórico, construcción y cronista
}

\section{RESUMEN}

La crónica, desde hace mucho tiempo se ha utilizado en los medios de comunicación, fundamentalmente en el periodístico. En el área deportiva brasileña, la crónica aborda las diferentes modalidades, principalmente el fútbol, que servirá como referencia para la discusión del nacimiento de la crónica en Francia, de su construcción como género literario, de su llegada a Brasil y su desarrollo como género nacional y del papel del cronista en su transformación. Este artículo hace una revisión de literatura para construir el histórico de la crónica en Brasil, asociando el fútbol a la "nacionalización" y difusión de este género narrativo.

PALABRAS-CLAVES: fútbol - crónica deportiva - cronista

\section{NOTAS}

1 Elias (1994, p. 68), sugere que "o aparecimento mais ou menos súbito de palavras em línguas quase sempre indica mudanças na vida do próprio povo, sobretudo quando os novos conceitos estão destinados a se tornarem fundamentais e de longa duração como esses", 
em referência ao surgimento de palavras correspondentes ao termo civilitas, com o sentido dado por Erasmo em seu tratado De civilitate morum puerilium, atendendo às necessidades sociais da época.

2 Ramadan (1997a, p 66) relaciona o sentir e o imaginar como matérias-primas do entendimento da metáfora: "A metáfora surge como um resultado lingüístico, uma estratégia cognitiva de um processo de manipulação da realidade, em que a imaginação e o sentimento concorrem para a aquisição de um valor semântico".

3 Pierre Plancher, livreiro francês, funda, em 1827, o Jornal do Comércio no Rio de Janeiro, e "dentro da linha evolutiva traçada para a crônica como gênero tipicamente brasileiro, presencia-se, nas décadas de 60 e 70, o surgimento de uma geração de cronistas que, ao lado de Rubem Braga, imprimem alta qualidade literária aos textos: Paulo Mendes Campos, Nelson Rodrigues, Cecília Meireles, Otto Lara Rezende, Fernando Sabino e Clarice Lispector" (RAMADAN, 1997b, p. 50).

4 Em Ribeiro e Pires (2005, p. 7), um entrevistado, cronista esportivo em Sergipe, relata sobre o esporte dentro da editoria jornalística: "no começo, $[\ldots]$ os jornais não gostavam de esportes não, era política. Prá se botar uma nota era um problema! [...], aí eu pegava uma notinha, entrava de mansinho [...]. Às vezes até, Paulo Costa dizia: já vem você com suas notas de futebol, né?!".

5 "Tornado negócio sério, o futebol precisava também ser reconhecido socialmente como assunto sério, como, por exemplo, a economia. A linguagem veio auxiliar no processo de elevação de status do futebol como coisa séria" (OLIVEIRA, 1996, p. 24).

6 Esse desinteresse estaria relacionado com o papel econômico que o futebol desempenhava na sociedade: "Sem valor econômico e considerado vulgar, os historiadores, tal qual os sociólogos, insistem em não perceberem o esporte como um objeto de estudo capaz de mostrar as mais tênues nuanças das relações sociais que, fora da lógica esportiva, parecem excludentes, como a competição e a cooperação ou o conflito e a harmonia" (NORMANDO, 2003).

7 Para Ramadan (1997a, p. 14), "trabalhada [...] nos jornais, é natural que a crônica adquira desses sua principal característica: a informação". 
8 Nota-se aqui a perda de força pela Academia Brasileira de Letras, que se transformou em "uma entidade que congrega intelectuais mas sem a força e sem a repercussão de outras épocas" (CALDAS, 1990, p. 183).

9 'A percepção de eventos que se produzem 'sucedendo-se no tempo' pressupõe, com efeito, existirem no mundo seres que sejam capazes, como os homens, de identificar em sua memória acontecimentos passados, e de construir mentalmente uma imagem que os associe a outros acontecimentos mais recentes, ou que estejam em curso" (ELIAS, 1998, p. 33).

10 Segundo Ramadan (1997a, p. 13): "Essa interpretação decorre das várias opções de focalização da história, condicionadas pelo ponto de vista do narrador".

\section{REFERÊNCIAS}

BENDER, F.; LAURITO, I. A crônica: história, teoria e prática. São Paulo: Scipione, 1993.

BOTELHO, A. R. M. Da geral à tribuna, da redação ao espetáculo: a imprensa esportiva e a popularização do futebol (1900-1920). In: SILVA, F. C. T. da; SANTOS, R. P. dos (Orgs.). Memória social dos esportes: futebol e política: a construção de uma identidade nacional. Rio de Janeiro: Mauad - Faperj, 2006. p. 313-335.

BURKE, P. Hibridismo cultural. São Leopoldo: Unisinos, 2003.

CALDAS, W. O pontapé inicial: memória do futebol brasileiro. São Paulo: Ibrasa, 1990.

COELHO, F. O. Futebol e produção cultural no Brasil: a construção de um espaço popular. In: SILVA, F. C. T. da; SANTOS, R. P. dos (Orgs.). Memória social dos esportes: futebol e política: a construção de uma identidade nacional. Rio de Janeiro: Mauad - Faperj, 2006. p. 228-258.

COSTA, A. C. B. Bate-bola com a crônica: o futebol, o jornalismo e a literatura brasileira. 2001. 80 f. Projeto Experimental do Curso de Comunicação Social. Faculdade de Comunicação - Universidade Federal de Juiz de Fora, Juiz de Fora, 2001. 
ELIAS, N. O processo civilizador: uma história dos costumes. Rio de Janeiro: Jorge Zahar, 1994. v. 1.

. Sobre o tempo. Rio de Janeiro: Jorge Zahar, 1998.

LUCENA, R. de F. O esporte na cidade. Campinas: Autores Associados, 2001.

. A crônica como gênero que introduziu o esporte no Brasil. Revista Brasileira de Ciências do Esporte, Campinas, v. 25, n. 1, p. 159-171, set. 2003.

MARQUES, J. C. O futebol ao rés do chão. In: CONGRESSO BRASILEIRO DE CIÊNCIAS DA COMUNICAÇÃO, 23., 2000, Manaus. Anais... Manaus: Intercom - GT Esporte e Mídia, 2000. 1. CDROM.

MOISÉS, M. A criação literária. 10. ed. São Paulo: Cultrix, 1982.

NORMANDO, T. S. O futebol como objeto de investigação acadêmica. EFDeportes Revista Digital, n. 58, mar. 2003. Disponível em <http:// www.efdeportes.com>. Acesso em: 30 jul. 2006.

OLIVEIRA, M. do C. L. de. Futebol na imprensa: uma releitura histórica. Pesquisa de campo: Revista do Núcleo de Sociologia do Futebol/ Uerj, Rio de Janeiro, n. 3/4, p. 21 - 36, 1996.

PEREIRA, L. A. de M. Footballmania: uma história social do futebol no Rio de Janeiro, 1902-1938. Rio de Janeiro: Nova Fronteira, 2000.

POLETTO, J. História, memória, ficção. Revista Eletrônica de Letras do DACEX, Curitiba, n. 6, 2003. Disponível em <www.cefetpr.br/deptos/dacex/revista.htm>. Acesso em: 9 dez. 2005.

RAMADAN, M. I. B. A crônica de Armando Nogueira: metáforas e imagens míticas. 1997. 145 f. Dissertação [Mestrado em Língua Portuguesa] - Pontifícia Universidade Católica de São Paulo, São Paulo, $1997 \mathrm{a}$.

. Crônica de futebol: um subgênero. Pesquisa de Campo: Revista do Núcleo de Sociologia do Futebol/Uerj. Rio de Janeiro, n. 5, p. 45-68, $1997 b$. 
RIBEIRO, S. D. D.; PIRES, G. De L. Jornalismo esportivo e futebol em Aracaju/SE: recortes históricos de um "casamento feliz". In: CONGRESSO BRASILEIRO DE CIÊNCIAS DO ESPORTE, 14., 2005, Porto Alegre. Anais... Porto Alegre: Conbrace - GTT Comunicação e Mídia, 2005. 1. CD-ROM.

RODRIGUES, N. Mário Filho, o criador de multidões. In: MARON FILHO, O.; FERREIRA, R. (Orgs.). Fla-Flu... e as multidões despertaram. Rio de Janeiro: Europa, 1987. p. 136-138.

SALVADOR, M. A.; et al. A imprensa e a memória do futebol. In: CONGRESSO BRASILEIRO DE CIÊNCIAS DO ESPORTE, 14., 2005, Porto Alegre. Anais... Porto Alegre Conbrace - GT Comunicação e Mídia, 2005. 1. CD-ROM.

SÁ, J. de. A crônica. 6. ed. São Paulo: Ática, 2002.

TROUCHE, A. L. G. Será este, o país do futebol? Hispanista, Niterói, v. 3, n. 10, jun./ago., 2002. Disponível em < http://www.hispanista. com.br/revista/rosto.htm >. Acesso em: 2 jun. 2006.

Recebido: 26 de setembro de 2006 Aprovado: 23 de outubro de 2006

Endereço para correspondência: Felipe Rodrigues da Costa Rua José Vivácqua, 77, Bairro Jabour Vitória - Espírito Santo CEP 29075-250

E-mail: feliperodrigues@proteoria.org 
